\title{
Evidence for genetic monogamy and female-biased dispersal in the biparental mouthbrooding cichlid Eretmodus cyanostictus from Lake Tanganyika
}

\author{
MARTIN I. TAYLOR, ${ }^{*}$ JOSEPHINE ISABELLE MORLEY,†CIRO RICO $\S$ and SIGAL BALSHINE \\ *School of Biological Sciences, University of East Anglia, Norwich NR4 7TJ, UK, †Department of Zoology, University of Cambridge \\ CB2 3EJ, UK, §Estacion Biologica Donana, Apartado 1056, E-41080, Seville, Spain, ¥Department of Psychology, McMaster University, \\ 1280 Main Street, West Hamilton, Ontario, L8S 4K1, Canada
}

\begin{abstract}
In this study, we investigate whether apparent social monogamy (where a species forms a pair bond but may participate in copulations outside the pair bond) corresponds with genetic monogamy (where individuals participate only in copulations within a pair bond) in a biparental mouthbrooding cichlid fish, Eretmodus cyanostictus, from Lake Tanganyika, Africa. Our findings suggest that E. cyanostictus is both socially and genetically monogamous and that monogamy may result from limited opportunities for polygyny, rather than from reproductive benefits of monogamy. Mating systems are believed to influence the relative rate of dispersal of the sexes, and our results suggest that E. cyanostictus displays female-biased dispersal, providing some support for the 'resource competition' hypothesis driving sex-biased dispersal.
\end{abstract}

Keywords: Cichlidae, Eretmodine, mating systems, microsatellites, sex-biased dispersal

\section{Introduction}

The study of animal mating systems has been revolutionized over the last decade by the development of the DNA-based techniques for parental assignment (Longmire et al. 1992; Leisler \& Wink 2000), and this has revealed hitherto unexpected complexity in the mating systems of many taxa. For example, 30 years ago monogamy was accepted as the predominant mating system for birds. It is now recognized that genetic monogamy is the exception rather than the rule: less than $10 \%$ of socially monogamous birds (where pair bonds are formed but copulations outside the pair bond may occur) also show genetic monogamy (where there are no copulations outside the pair bond) (Birkhead \& Møller 1998; Morell 1998). Genetic monogamy also appears rare in fishes and to our knowledge has been documented only twice before: in the internally fertilizing seahorse Hippocampus subelongatus (Jones et al. 1998; Kvarnemo et al. 2000) and in the externally fertilizing large mouth bass (Micropterus salmoides) (DeWoody et al. 2000).

Correspondence: Martin Taylor. E-mail: nitram8@hotmail.com
Monogamy is expected if two individuals are needed to (1) effectively feed, incubate or guard young (Lack 1968; Barlow 1984); (2) guard a territory (Barlow 1984); or (3) because mate availability is low (Ghiselin 1969; Brotherton \& Rhodes 1996). These factors do not seem to apply for Eretmodus cyanostictus, a small, socially monogamous, biparental mouthbrooding cichlid fish, from Lake Tanganyika, Africa. Females initially brood small clutches in their buccal (mouth) cavities, before transferring them to the male, who broods them until release (Kuwamura et al. 1989). Monogamy does not appear to be maintained by the need to defend young jointly - parents do not defend newly released young, and each sex is capable of incubating the entire clutch orally until maturity (Morley 2000). Nor does monogamy appear to be maintained by the need to defend territories jointly - single individuals can retain their territories after experimental removal of one member of a breeding pair (Morley \& Balshine 2002). Moreover, a low density of potential partners is unlikely to maintain monogamy, as individuals gained new partners quickly following experimental removal of male or female mates (Morley \& Balshine 2002). In cichlid fishes, biparental mouthbrooding is thought to be an intermediate and 
unstable stage between biparental substrate guarding and maternal mouthbrooding (Barlow 1963; Goodwin et al. 1998) and, consequently, the persistence of social monogamy remains a mystery in this species. The first aim of this study is to investigate whether social monogamy (assumed from behavioural observations on E. cyanostictus) translates to true genetic monogamy.

The genetic mating system may also have important implications for the relative rates of dispersal of each sex. Male-biased dispersal has been demonstrated previously in a polygynandrous cichlid fish from Lake Malawi (Knight et al. 1999). Three hypotheses suggest that male-biased dispersal will occur in polygynous species. These are: (1) the 'resource-competition hypothesis' (Greenwood 1980), that states that the philopatric sex will be the one that benefits most from a familiarity with its natal area; (2) the 'local mate competition' hypothesis (Perrin \& Mazalov 2000) which suggests that individuals disperse to avoid competing (for mates) with relatives, thus increasing their inclusive fitness; and (3) the 'inbreeding avoidance hypothesis' (Pusey 1987; Perrin \& Mazalov 2000), which suggests that the sex incurring the greatest cost from inbreeding will disperse. In monogamous species, female-biased dispersal is predicted by the 'resource competition' hypothesis. Males are likely to benefit more than females from familiarity with birth site as they help to rear young, and need to acquire and defend a territory with sufficient resources to attract a female (Favre et al. 1997). No bias is predicted in monogamous species by the inbreeding avoidance or local mate competition hypotheses. Therefore, if E. cyanostictus are genetically monogamous, we would expect either a female bias in dispersal, providing support for the resource competition hypothesis, or no bias in dispersal, providing evidence for the inbreeding or mate competition avoidance hypotheses. We predict male-biased dispersal if cuckoldry is common. To investigate whether a sex-bias in dispersal exists in E. cyanostictus and its direction (if any), we compared the degree of relatedness between pairs of males and females in the field.

\section{Materials and methods}

\section{Sample collection}

The field study was conducted in an area $\left(100 \mathrm{~m}^{2}\right.$ at $3 \mathrm{~m}$ depth) on the southern shore of Lake Tanganyika, northwest of Mpulungu, Zambia in Kasakalawe Bay, 100 m east of Kasakalawe Village. Pairs of E. cyanostictus were identified by swimming along a transect line in the study area, and a numbered rock was positioned on each pair's territory boundary. All fish were identified reliably by their location and the unique pattern of blue spots on their body. Behavioural observations with scuba were conducted on pairs each week from 4 February to 14 April 1998. Detailed descriptions of the site, pair identity and the behavioural watches can be found elsewhere (Morley 2000; Morley \& Balshine 2002). In mid-April 1998, 13 adult pairs and their entire clutches, a single brooding adult male and one additional adult pair without a clutch, were caught using monofilament nets. In total 203 eggs and fry, as well as 14 adult females and 15 adult males, were collected for this study. Fin clips from both parents and the entire clutches (whole eggs or fry) were preserved in 95\% ethanol.

\section{DNA preparation and amplification}

Total DNA was extracted from eggs/fry and fin clips using proteinase-K digestion followed by the Bilatest magnetic bead extraction kit (Bilatec AG, Germany), using the Roboseq 4204 S robot (MWG). Extracted DNA was resuspended in $100 \mu \mathrm{L}$ of Sigma tissue culture water (Sigma-Genosys).

\section{Microsatellite amplification}

All offspring and adult samples were screened for variation at each of three SSR loci, one of which is a perfect dinucleotide repeat (Pzeb1, van Oppen et al. 1997), one is an imperfect dinucleotide repeat (TmoM25, Zardoya et al. 1996) and one is a compound repeat (TmoM5, Zardoya et al. 1996). Adults were screened at two additional loci, UNH002 (Kellogg et al. 1995) and Pzeb3 (van Oppen et al. 1997), both of which are perfect dinucleotide repeats. Polymerase chain reactions (PCRs) were performed in a MJ Research PTC-200 thermal-cycler under the following conditions: $94^{\circ} \mathrm{C}, 120 \mathrm{~s}$, followed by five cycles of $94^{\circ} \mathrm{C}$, $45 \mathrm{~s} ; \mathrm{A}{ }^{\circ} \mathrm{C}, 45 \mathrm{~s} ; 72{ }^{\circ} \mathrm{C}, 45 \mathrm{~s}$, followed by 30 cycles of $91^{\circ} \mathrm{C}$, $30 \mathrm{~s} ; \mathrm{A}{ }^{\circ} \mathrm{C}, 30 \mathrm{~s} ; 72{ }^{\circ} \mathrm{C}, 30 \mathrm{~s}$, followed by $72{ }^{\circ} \mathrm{C}, 10 \mathrm{~min}$. The annealing temperatures (A) are given in Table 1 . Ten $\mu \mathrm{L}$ reaction mixes consisted of $1 \mu \mathrm{L}(\approx 20 \mathrm{ng})$ template DNA, $0.5 \mu \mathrm{m}$ of each primer, $200 \mu \mathrm{m}$ of each dNTP, 0.26 units Taq polymerase (Bioline), $1 \mu \mathrm{L} 10 \times$ reaction buffer (Bioline) and $1.5 \mathrm{~mm}$ magnesium chloride. Amplified products were resolved on an ABI 377 automated sequencer (Applied Biosystems). genescan and genotyper software (Applied Biosystems) were used to size the fragments.

\section{Data analysis}

Pop100gene (http://www.montpellier.inra.fr/URLB/ pop100gene/pop100gene.html) was used to estimate allele numbers, and observed and unbiased expected heterozygosities at each locus. cervus 2.0 (Marshall et al. 1998) was used to calculate overall exclusion probabilities (the expected proportion of individuals in the population that would be rejected as parents of an offspring given that the maternal genotype was known) for the three loci. Pairwise relatedness (R) was estimated for the adult samples using five microsatellite loci with the program relatedness 
Table 1 The five microsatellite loci used for genetic analysis. Expected $\left(\mathrm{H}_{\mathrm{E}}\right)$ and observed $\left(\mathrm{H}_{\mathrm{O}}\right)$ heterozygosities were estimated using the popgene computer program (available at: http:// www.montpellier.inra.fr/URLB/pop100gene/pop100gene.html)

\begin{tabular}{llccccccc}
\hline Locus & Label & A & N & $\begin{array}{c}\text { No. of } \\
\text { alleles }\end{array}$ & Min & Max & $\mathrm{H}_{\mathrm{O}}$ & $\mathrm{H}_{\mathrm{E}}$ \\
\hline Pzeb1 & FAM & 55 & 29 & 11 & 129 & 154 & 0.72 & $0.84^{*}$ \\
TmoM25 & HEX & 60 & 29 & 11 & 337 & 365 & 0.86 & 0.85 \\
TmoM5 & FAM & 55 & 29 & 25 & 315 & 377 & 0.79 & 0.92 \\
Pzeb3 & HEX & 55 & 29 & 4 & 318 & 324 & 0.28 & 0.30 \\
UNH002 & HEX & 52 & 29 & 16 & 161 & 205 & 0.86 & 0.82 \\
\hline
\end{tabular}

A = PCR annealing temperature, $\mathrm{N}=$ no. adults typed, $\min =$ minimum allele size, $\max =$ maximum allele size. ${ }^{*}$ Significant deviation from Hardy-Weinberg equilibrium before (but not after) Bonferroni correction.

5.08 (Queller \& Goodnight 1989). Separate matrices of pairwise relatedness were produced for 15 males and 14 females and the average relatedness of each individual to all other individuals of the same sex calculated [this reduces the effects of pseudoreplication (Knight et al. 1999)]. A twosample permutation test [rundom 1.0, (Jadwiszczack 2002)] was then performed to test for a difference in average relatedness between males and females. Permutation tests combine all data, randomly assign data to groups (male and female in this case), and then calculate the difference between the mean of the two groups. This is repeated $\mathrm{N}$ times (10 000 in the current study) and exact P-values obtained by comparing the difference between the means of the real data with the frequency distribution obtained from the permutated data.

\section{Results}

All the observational data suggested that E. cyanostictus was socially monogamous (Morley 2000). Thirteen adult pairs and their entire clutches, a single male with his clutch, and one additional adult pair without a clutch were genotyped. Only one member of each pair was found to be carrying eggs or young in their mouths. The mean number of offspring carried by individuals was 14.5. For the adult samples, the number of alleles per locus ranged from four in Pzeb3 to 25 in TmoM5. Unbiased expected heterozygosity $\left(\mathrm{H}_{\mathrm{E}}\right)$ ranged from 0.30 in Pzeb3 to 0.92 in TmoM5 (Table 1). The total exclusionary power for the three loci combined was 0.98 .

Of the 14 clutches genotyped, 202 individuals displayed genotypes consistent with their having been sired by the assumed father. A single individual (the 203rd individual) showed an allele inconsistent with either parent at locus TmoM5. As the other two loci were consistent with the parental genotypes, we assume a mutation occurred at a

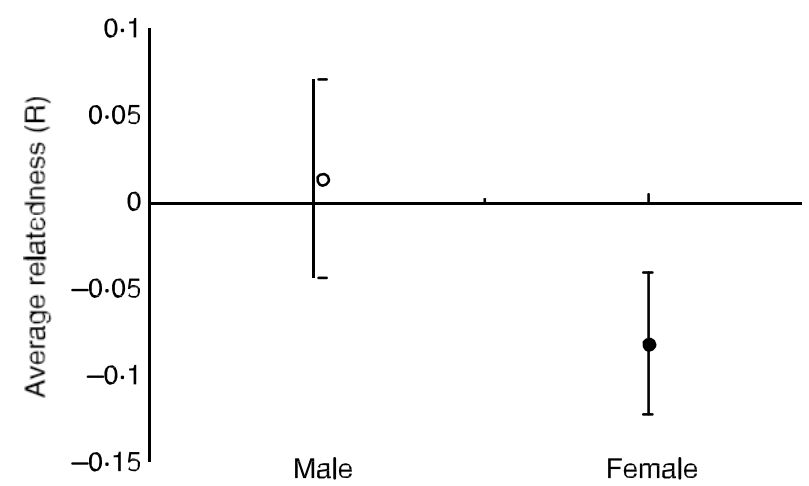

Fig. 1 Average pairwise relatedness of each male to all other males (no. males $=15$ ) vs. average pairwise relatedness of each female to all other females (no. females $=14$ ) in a population of E. cyanostictus. Error bars are standard deviation.

single allele in a single locus in this individual, resulting in a reduction in allele size from 133 to 131 - a single repeat unit. Spontaneous mutations have been documented in other parentage studies (Jones et al. 1999; McCoy et al. 2001). Therefore, we concluded that all 14 clutches showed genotypes consistent with a single pair of parents - no more than four alleles per locus.

Evidence for sex-biased dispersal

The average pairwise relatedness of each individual to all other individuals of the same sex ranged between -0.094 and 0.013 for males and -0.0041 and -0.177 for females. Males were found to be significantly more closely related on average [mean \pm standard deviation $(\mathrm{SD})=$ $0.013 \pm 0.057$ ] than were females (mean \pm SD $=-0.0817 \pm$ 0.04) (two-sample permutation test, 10000 randomizations, two-tailed $\mathrm{P}<0.0001$, Fig. 1).

\section{Discussion}

\section{Maintenance of monogamy}

We genotyped all offspring from 14 clutches, and the genotypes of each clutch were consistent with having been sired by a single male and female. Thus, the results of this study indicate E cyanostictus is genetically and socially monogamous.

The tribe Eretmodini consists of four nominal species in three genera. E. cyanostictus and Tanganicodus irsacae are biparental mouthbrooding species, while Spathodus marlieri and S. erythrodon are maternal mouthbrooding species. Biparental mouthbrooding is thought to be derived from biparental substrate guarding, and intermediate to uniparental mouthbrooding (Barlow 1963; Gittleman 1981; Balshine-Earn \& Earn 1998; Goodwin et al. 1998). The 
reasons why biparental mouthbrooding has persisted in two of the three genera remain obscure. Female T. irsacae can brood offspring to a viable size without the help of the male (Kuwamura et al. 1989), and this also is the case for E. cyanostictus (Morley 2000).

There are various factors that may favour the maintenance of monogamy in E. cyanostictus. First, the malebiased sex ratio (Morley \& Balshine 2003) might make it difficult for males to find additional mating partners if they desert females after spawning (although females could desert males after transferring their broods). Second, E. cyanostictus retains only a vestigial swim bladder (Brichard 1989), which allows it to 'sit' on the substrate and avoid battering by wave action. Prolonged swimming, which is necessary when searching for new mates or territories, may be considerably costly compared with fish species with functioning swim bladders. Third, laboratory experiments suggest that both sexes guard their mates and repel intruders, reacting more strongly to same-sex than opposite-sex intruders (Morley 2000). These findings suggest that monogamy may occur in E. cyanostictus because of constraints on polygyny for both sexes rather than benefits to monogamy itself. This also appears to be the reason for monogamy in particular bird species (Krebs \& Davies 1983; Piper et al. 1997).

\section{Evidence for sex-biased dispersal}

The data from this study suggest that females disperse more than males in E. cyanostictus, which is the opposite situation to that found in a polygynandrous cichlid from Lake Malawi (Knight et al. 1999). Several hypotheses may shed light on the female biased dispersal in this genetically monogamous, rock-dwelling cichlid. Inbreeding avoidance (Bengtsson 1978; Parker 1979; Waser et al. 1986) may be important, as significant genetic structure is evident on a continuous rocky shoreline not divided by physical barriers, suggesting that E. cyanostictus are poor dispersers (Taylor et al. 2001). Theory predicts that the sex that incurs the highest cost of inbreeding should be the dispersing sex (Perrin \& Mazalov 1999). However, in genetically monogamous mating systems, such as E. cyanostictus' (see above), the cost of inbreeding should be identical for males and females, as both would be forced to accept a single inbred mating opportunity at the expense of a single outbred mating opportunity. There should be no asymmetry in inbreeding costs in monogamous species, and no sex-bias in dispersal, assuming equal sex-ratios. Therefore, we would expect no sex-bias in dispersal if inbreeding avoidance plays a significant role in driving dispersal in E. cyanostictus.

The 'local mate competition' hypothesis also predicts no bias in dispersal in monogamous systems as both sexes are equally affected by local mate competition. Hence our data of female biased dispersal do not provide support for this hypothesis.

The 'resource competition hypothesis' (Greenwood 1980) focuses on the relative advantages of philopatry for each sex, and predicts that the philopatric sex will be the sex that benefits most from a familiarity with its birth site. E. cyanostictus males may best enhance their own fitness by defending a high quality territory that attracts females and provides high quality resources (food and shelter) for the offspring. If males take a significant responsibility in acquiring and defending the breeding territory, then the advantages of philopatry will be greater for male E. cyanostictus than for females. Currently we do not know which sex acquires the breeding territory, although males do defend the territory more vigorously than females (Morley \& Balshine 2003). More research is now needed to investigate the hypothesis that female-biased dispersal is a result of the benefits of philopatry for males.

This study is based on a limited set of samples collected from a single population, and consequently any conclusions drawn from the data must be treated with some caution. While the population sampled in this study appears to be genetically monogamous and to exhibit female-biased dispersal, we highlight that other populations may exhibit different behavioural characteristics.

In summary, E. cyanostictus appears to be both behaviourally and genetically monogamous. Such monogamy may be maintained through constraints on polygyny rather than advantages to monogamy, and in contrast with polygynandrous cichlids, E. cyanostictus displays femalebiased dispersal.

\section{Acknowledgements}

A grant from the Pamela Salter Charitable Trust awarded to MT, JM and SB supported the laboratory costs for this study. The field research was supported by a BBSRC studentship to JM, and a Royal Society Grant and NSERC grant to SB. We wish to thank the Zambian Ministry of Agriculture, Food and Fisheries, and especially Mr John Mwango and Mr Leonard Mwape, for permission to conduct fieldwork in Zambia. We would also like to thank Pia Grubaur, Gudrun Pachler, Michael Taborsky and Fritz Trillmich for their assistance in the field. We also thank John Avise, Nick Goodwin, Sara Goodacre, Godfrey Hewitt, Bryan Neff, Trevor Pitcher, Phil Stephens and Allison Surridge, for helpful discussion. We would also like to thank two anonymous referees for comments of a previous draft of the manuscript.

\section{References}

Balshine-Earn S, Earn DJD (1998) On the evolutionary pathway of parental care in mouth-brooding cichlid fish. Proceedings of the Royal Society of London Series B, Biological Sciences, 265, 22172222.

Barlow GW (1963) Evolution of behaviour. Science, 139, 851- 852. Barlow GW (1984) Patterns of monogamy among teleost fishes. Archiv Fur Fischereiwissenschaft, 35, 75-123. 
Bengtsson BO (1978) Avoiding inbreeding: at what cost? Journal of Theoretical Biology, 73, 439-444.

Birkhead TR, Møller AP (1998) Sperm Competition and Sexual Selection. Academic Press, London.

Brichard P (1989) Cichlids and All the Other Fishes of Lake Tanganyika. TFH Publications, Neptune City, NJ.

Brotherton PNM, Rhodes A (1996) Monogamy without biparental care in a dwarf antelope. Proceedings of the Royal Society of London Series B, Biological Sciences, 263, 23-29.

DeWoody JA, Fletcher DE, Wilkins SD, Nelson WS, Avise JC (2000) Genetic monogamy and biparental care in an externally fertilizing fish, the largemouth bass (Micropterus salmoides). Proceedings of the Royal Society of London Series B, Biological Sciences, 267, 2431-2437.

Favre L, Balloux F, Goudet J, Perrin N (1997) Female-biased dispersal in the monogamous mammal Crocidura russula: evidence from field data and microsatellite patterns. Proceedings of the Royal Society of London Series B, Biological Sciences, 264, 127-132.

Ghiselin MT (1969) The evolution of hermaphroditism among animals. Quarterly Reviews in Biology, 44, 189-208.

Gittleman JL (1981) The phylogeny of parental care in cichlids. Animal Behaviour, 29, 936-941.

Goodwin NB, Balshine-Earn S, Reynolds JD (1998) Evolutionary transitions in parental care in cichlid fish. Proceedings of the Royal Society of London Series B, Biological Sciences, 265, 2265-2272.

Greenwood PJ (1980) Mating systems, philopatry and dispersal in birds and mammals. Animal Behaviour, 28, 1140-1162.

Jadwiszczack P (2002) rundom projects: an application for randomization and bootstrap testing. Available from: http:pjadw.tripod.com

Jones AG, Kvarnemo C, Moore GI, Simmons LW, Avise JC (1998) Microsatellite evidence for monogamy and sex-biased recombination in the Western Australian seahorse Hippocampus angustrus. Molecular Ecology, 7, 1497-1506.

Jones AG, Rosenqvist G, Berglund A, Avise JC (1999) The genetic mating system of a sex-role-reversed pipefish (Syngnathus typhle): a molecular inquiry. Behavioral Ecology and Sociobiology, 46, 357-365.

Kellogg KA, Markert JA, Stauffer JR, Kocher TD (1995) Microsatellite variation demonstrates multiple paternity in lekking cichlid fishes from Lake Malawi, Africa. Proceedings of the Royal Society of London Series B, Biological Sciences, 260, 79-84.

Knight ME, van Oppen MJH, Smith HL et al. (1999) Evidence for male-biased dispersal in Lake Malawi cichlids from microsatellites. Molecular Ecology, 8, 1521-1527.

Krebs JR, Davies NB (1983) An Introduction to Behavioural Ecology, 3rd edn. Blackwell Scientific Publications, Oxford.

Kuwamura T, Nagoshi M, Sato T (1989) Female-to-male shift of mouthbrooding in a cichlid fish, Tanganicodus irsacae, with notes on breeding habits of 2 related species in Lake Tanganyika. Environmental Biology of Fishes, 24, 187-198.

Kvarnemo C, Moore GI, Jones AG, Nelson WS, Avise JC (2000) Monogamous pair bonds and mate switching in the Western Australian seahorse Hippocampus subelongatus. Journal of Evolutionary Biology, 13, 882-888.

Lack D (1968) Ecological Adaptations for Breeding in Birds. Methuen Ltd, London.

Leisler B, Wink M (2000) Frequencies of multiple paternity in three Acrocephalus species (Aves Sylviidae) with different mating systems (A. palustris, A. arundinaceus, A. paludicola). Ethology, Ecology and Evolution, 12, 237-249.
Longmire JL, Gee GF, Hardekopf CL, Mark GA (1992) Establishing paternity in whooping-cranes (Grus americana) by DNA analysis. Auk, 109, 522-529.

Marshall TC, Slate J, Kruuk LEB, Pemberton JM (1998) Statistical confidence for likelihood-based paternity inference from natural populations. Molecular Ecology, 7, 639-655.

McCoy EE, Jones AG, Avise JC (2001) The genetic mating system and tests for cuckoldry in a pipefish species in which males fertilise eggs and broods externally. Molecular Ecology, 10, 17931800.

Morell V (1998) A new look at monogamy. Science, 281, 1982-1983.

Morley JI (2000) Intraspecific competition and monogamy in the cichlid fish, Eretmodus cyanostictus. PhD thesis, Cambridge University.

Morley JI, Balshine S (2002) Faithful fish: territory and mate defence favour monogamy in an African cichlid fish. Behavioral Ecology and Sociobiology, 52, 326-331.

Morley JI, Balshine S (2003) Reproductive biology of Eretmodus cyanostictus, a cichlid fish from Lake Tanganyika. Environmental Biology of Fishes, 66, 169-179.

van Oppen MJH, Rico C, Deutsch JC, Turner GF, Hewitt GM (1997) Isolation and characterization of microsatellite loci in the cichlid fish Pseudotropheus zebra. Molecular Ecology, 6, 387-388.

Parker GA (1979) Sexual selection and sexual conflict. In: Sexual Selection and Reproductive Competition in Insects (eds Blum SBS, Blum NA), pp. 123-166. Academic Press, New York.

Perrin N, Mazalov V (1999) Dispersal and inbreeding avoidance. American Naturalist, 154, 282-292.

Perrin N, Mazalov V (2000) Local competition, inbreeding, and the evolution of sex-biased dispersal. American Naturalist, 155, 116127.

Piper WH, Evers DC, Meyer MW et al. (1997) Genetic monogamy in the common loon (Gavia immer). Behavioral Ecology and Sociobiology, 41, 25-31.

Pusey AE (1987) Sex-biased dispersal and inbreeding avoidance in birds and mammals. Trends in Ecology and Evolution, 2, 295-299.

Queller DC, Goodnight KF (1989) Estimation of genetic relatedness using allozyme data. Evolution, 43, 258-275.

Taylor MI, Ruber L, Verheyen E (2001) Microsatellites reveal high levels of population substructuring in the species-poor Eretmodine cichlid lineage from Lake Tanganyika. Proceedings of the Royal Society of London Series B, Biological Sciences, 268, 803-808.

Waser PM, Austad SN, Keane B (1986) When should animals tolerate inbreeding? American Naturalist, 128, 529-537.

Zardoya R, Vollmer DM, Craddock C et al. (1996) Evolutionary conservation of microsatellite flanking regions and their use in resolving the phylogeny of cichlid fishes (Pisces: Perciformes). Proceedings of the Royal Society of London Series B, Biological Sciences, 263, 1589-1598.

Martin I. Taylor is a Senior Research Associate interested in the evolution and behavioural ecology of African cichlid fishes and population genetics of fishes. Sigal Balshine is an Assistant Professor studying reproductive behaviour with specific interests in the evolution of parental care, cooperative breeding and sperm competition in cichlid fishes. Josephine Morley studied the behavioural ecology of E. cyanostictus for her $\mathrm{PhD}$ at Cambridge University. Ciro Rico is a lecturer in Molecular Ecology with a particular interest in fishes. 